\title{
RECONHECIMENTO E DIREITO À DIFERENÇA: TEORIA CRÍTICA, DIVERSIDADE E A CULTURA DOS DIREITOS HUMANOS
}

\author{
RECOGNITION AND RIGHT OF DIFFERENCE: CRITICAL THEORY, DIVERSITY AND CULTURE OF \\ HUMAN RIGHTS
}

Eduardo C. B. Bittar*

\begin{abstract}
Resumo:
Esta investigação, partindo de concepções frankfurtianas, empreende um movimento em direção à afirmação e fundamentação filosófica da diversidade humana na cultura dos direitos humanos. Ao tratar das transformações recentes da sociedade, reafirmar o compromisso com o espírito democrático de uma ética pluralista. Neste contexto, a categoria do reconhecimento (Anerkennung) serve de base filosófica para a justificativa do direito à diferença.
\end{abstract}

Palavras-chave: Reconhecimento. Diversidade. Direitos Humanos.

\begin{abstract}
:
From frankfurtians studies, this work intends to analyze the construction and the foundation of a theory of the human diversity in a human rights culture. Taking into the consideration the recent society transformations, it reaffirms the commitment with a democratic spirit of a plural ethics. The category of recognition (Anerkennung) is the philosophical basis to the right of difference.
\end{abstract}

Keywords: Recognition. Diversity. Human Rights.

1. A ruptura de Maio de 68: o pluralismo social e a emergência da luta pelo reconhecimento da diferença

Transformações recentes da sociedade contemporânea permitiram requalificar o sentido de inúmeras experiências, nos campos, culturais, comportamentais, políticos e jurídicos. A reflexão que inclui, da história recente, a análise dos efeitos de Maio de 68 para a agenda das percepções reflexivas das mudanças das categorias filosóficas, e de sua absorção pela vida político-jurídica, é aquela que destaca a importância da esfera pública para a construção de novas identidades sociais, afinal a luta por direitos é uma luta histórica. No entanto, nos registros da dogmática jurídica, e, mesmo, da história do direito, raramente identifica-se no marco de Maio de 68 o epicentro de algum processo de significação jurídica. Apesar disso, pode-se extrair da força do movimento estudantil, e de sua capacidade de mobilizar a atenção pública para questões no contexto relevantes, uma

\footnotetext{
Livre-Docente e Doutor, Professor Associado do Departamento de Filosofia e Teoria Geral do Direito da Faculdade de Direito da Universidade de São Paulo, nos cursos de graduação e pós-graduação em Direito, e em Direitos Humanos. Presidente da Associação Nacional de Direitos Humanos (ANDHEP/ NEV-USP). Pesquisador-Sênior do Núcleo de Estudos da Violência da USP e Coordenador do Grupo de Pesquisa "Democracia, Justiça e Direitos Humanos: estudos de Escola de Frankfurt", junto ao NEV-USP. Professor e pesquisador do Mestrado em Direitos Humanos do UniFIEO. Membro Titular da Cátedra UNESCO-IEA/ USP de Educação para a Paz, Direitos Humanos, Democracia e Tolerância”.
} 
ruptura de significativa importância para a transformação das sociedades contemporâneas. Não pelo que Maio de $68 \mathrm{fez}$, mas pelo que simbolicamente legou. As fraturas deixadas neste ano consolidam de vez a sensação de crise da modernidade.

A dialética do esclarecimento é um marco neste sentido, pois desde os anos 40 já identificava o mal-estar na cultura funcionando no interior dos arquétipos modernos; nem somente de luzes vive a modernidade, mas de uma dialética de luzes e sombras. A Escola de Frankfurt, desde a sua primeira geração, capta e descreve não somente a barbárie da guerra e do genocídio, como também é capaz de apontar o estado das formas sociológicas e dos valores da sociedade do pós-guerra, alimentando o processo de eclosão da revolta estudantil, que se dá ao longo de diversos episódios, ao longo de todo o ano de 1968, em várias partes do mundo, considerando-se especialmente a França e a Alemanha. ${ }^{1}$ Dá-se, desde então, abertura ao debate filosófico e sociológico contemporâneos sobre a 'pós-modernidade'; um dos grandes legados teóricos desse período será exatamente a impossibilidade, em ciências sociais, de se ignorar o sentido desta expressão após essa data. Nesse sentido, a própria noção de direito hodierno deve muito a maio de 68 por sua atual conformação, e é por isso que não se pode pensar as categorias de justiça contemporâneas fora deste quadro histórico de compreensão.

Assim, Maio de 68 pode ser tomado como o momento histórico de quebra de padrões comportamentais, de luta contra a autoridade familiar, reivindicação de alteração nos padrões de regulação da vida acadêmica, de ampliação da demanda por radicalização da liberdade política, dos direitos de minorias, de redefinição do papel político da estética, de redefinição do papel da moral em direção ao pluralismo ético, de luta por redemocratização, e pelo reconhecimento da diferença, de ampliação da luta libertária pela sociedade civil organizada, questões que, em muitos de seus significados, redundaram em frutos muito concretos no plano da cultura e das relações humanas e sociais. Ademais, não se pode omitir o fato de que a atual redação da democrática Constituição Federal Brasileira de 1988 deve muito a estas lutas. A Constituição Cidadã, que também incorpora o legado da dignidade da pessoa humana, vindo da Declaração Universal de Direitos Humanos de 1948, representa, em nosso contexto, um bastião de lutas pela garantia ampla da liberdade, e, por isso, reflete os aquisitivos dos 20 anos que antecederam sua promulgação.

Nesse contexto, se torna legítimo pensar no reconhecimento da diferença e da peculiaridade de uma minoria (negros, mulheres, deficientes, sem-terra...), mais do que na pressuposição da igualdade genérica de todos (povo, cidadão). É recente, portanto, a percepção de que a noção de igualdade faz sombra à possibilidade de um reconhecimento da singularidade ou particularidade de cada qual. No contexto mais amplo de reformulação

\footnotetext{
A respeito, vide JAY, Martin. A imaginação dialética: história da Escola de Frankfurt e do Instituto de Pesquisas Sociais, 2008. p. 10 e ss.
} 
da Kritische Theorie, herdada das construções advindas dos estudos de Horkheimer e Adorno, de Marcuse e de Habermas, é no pensamento de Axel Honneth que se encontra amplo esteio, através da categoria do reconhecimento (Anerkennung), numa revisitação do pensamento do jovem Hegel, para a sustentação da lógica do direito à diferença. ${ }^{2}$

2. $\mathrm{O}$ direito à diferença e a interpretação da dignidade humana

O direito à diferença é uma ampliação, no interior da cultura do direito, da afirmação de formas de luta por reconhecimento. A ampliação elástica do conceito de direito, para abranger também a idéia de um direito à diferença, consolida a ambição de diferenciação, dentro de sociedades modernas que tendem a produzir homogeneização e padronização. É de modo reativo, portanto, que a luta pela diferença se inscreve, dialeticamente, ao lado da identidade de uma luta não interrompida por igualdade.

Por isso, o direito à diferença se distingue do direito à igualdade. Percebe-se que o mero decreto de igualdade de todos perante a lei não salvaguarda a possibilidade de realização do reconhecimento pleno, na vida social. Percebe-se, também, que esta versão da igualdade está falseada pelo pressuposto liberal de que a justiça como igualdade de direito é suficiente para provocar um equilíbrio nas relações intersubjetivas. Os estudos de Honneth permitem identificar que a noção de dignidade está, além do reconhecimento da igualdade jurídica, também no reconhecimento da diferença. Ao tratar da questão do surgimento da idéia de dignidade, Honneth bem identifica que “...uma parte não desconsiderável do que os princípios de honra, escalonados segundo o estamento, asseguravam até então ao indivíduo em termos de estima social migra para a relação jurídica reformada, onde alcança validade universal com o conceito de dignidade humana; nos catálogos modernos de direitos fundamentais, é garantida a todos os homens, em igual medida, uma proteção jurídica de sua reputação social...". ${ }^{3}$

Se os contornos semânticos internos do termo dignidade absorvem a idéia de honra, vindos da tradição pré-moderna, a honra tem a ver com distinção, e não com aquilo que é comum, mas com aquilo que é raro e próprio do singular: “...uma pessoa só pode se sentir valiosa quando se sabe reconhecida em realizações que ela justamente não partilha de maneira indistinta com todos os demais". ${ }^{4}$ Por isso, a luta por dignidade, atualmente, encontra qualidade para se realizar na dinâmica da exigência de reconhecimento

\footnotetext{
2 A respeito, vide HONNETH, Axel. Disrespect: the normative foundations of critical theory. Cambrigde: Polity, 2008; . Sofrimento de indeterminação: uma reatualização da filosofia do direito de Hegel. São Paulo: Editora Singular, 2007; . Luta por reconhecimento: a gramática moral dos conflitos sociais. Tradução de Luis Repa. São Paulo: Editora 34, 2003.

3 HONNETH, Axel. Luta por reconhecimento: a gramática moral dos conflitos sociais. Tradução de Luis Repa. São Paulo: Editora 34, 2003. p. 204.

4 Id. Ibid.
} 
da particularidade, exatamente por se inscrever num quadro de luta por diferenciação, reativamente a uma modernidade produtora do homogêneo.

É exatamente este perfil de incômodo que tem motivado a atuação dos movimentos sociais, principalmente nas últimas três décadas, o que vem a conferir um novo colorido neste debate na medida em que reclamam de modo central a quebra da igualdade de direito como forma e parâmetro de tratamento social. Ao formularem ações e políticas de integração que levam em conta o princípio da diferença estão insculpindo também a lógica da desigualdade como um parâmetro importante para a construção de justiça, na medida em que "...igualdade e desigualdade são os valores constitutivos da justiça. O que é único não pode ser comparado nem classificado, e, obviamente, entidades únicas tampouco podem ser iguais ou desiguais umas das outras". ${ }^{5}$ Por isso, o discurso contemporâneo sobre justiça tem se empenhado acerbamente no tratamento das diferenças. Se baseando nos estudos de Honneth, em Direito e democracia é Habermas quem afirma: "As condições concretas de reconhecimento, seladas por uma ordem jurídica legítima, resultam sempre de uma 'luta por reconhecimento'; e essa luta é motivada pelo sofrimento e pela indignação contra um desprezo concreto. A. Honneth mostra que é necessário articular experiências que resultam de atentados à dignidade humana para conferir credibilidade aos aspectos sob os quais, no respectivo contexto, aquilo que é igual tem que ser tratado de modo igual e aquilo que é diferente tem que ser tratado de modo diferente". ${ }^{6}$

Isto faz toda a diferença no plano das discussões sobre direitos humanos, e é curioso notar como o universalismo abstrato da tradição jusnaturalista vem cedendo campo a uma mais concreta e histórica visão dos direitos humanos, que contempla, inclusive, o olhar de uma antropologia filosófica sobre a qual se escudar. Isto se tornou visível no Brasil, no ano passado (2008), quando das comemorações dos 60 anos da Declaração Universal dos Direitos Humanos (1948). O direito à diferença tem isto de particular, a idéia de que é possível que sejamos iguais na diferença, este que foi o lema adotado pela Secretaria Especial de Direitos Humanos do Governo Federal (SEDH), no Brasil. Percebe-se, pois, que esta idéia tem contagiado a forma de se entender e praticar os direitos humanos, em direção a uma maior porosidade em direção ao relativismo. Tornou-se difícil ser indiferente ao direito à diferença, que é este que protege a condição humana, em suas

HELLER, Fehér. A condição política pós-moderna. Tradução Marcos Santarrita. Rio de Janeiro: Civilização Brasileira, 1998. p. 174-175. Em outro trecho, mais adiante: "Pode surgir a questão de não termos incluído o princípio "a cada um segundo suas necessidades" entre as idéias de justiça. Nós a excluímos bastante deliberadamente porque, ao contrário da crença disseminada, esse princípio não é uma idéia de justiça. Ao contrário, esse princípio nos manda ir além da justiça. Como todas as pessoas são únicas, não podem ser equalizadas, e assim a satisfação de todas as necessidades de todas as pessoas não pode se basear em comparação e classificação".

6 HABERMAS, Jürgen. Direito e democracia: entre facticidade e validade. Tradução de Flávio Beno Siebeneicher. Rio de Janeiro: Tempo Brasileiro, 2003. v. 2, p. 168-169. 
múltiplas expressões, única forma de reconhecer como seres humanos vivem e sofrem concretamente, para que haja a possibilidade de implementação e de direcionamento mais exato de políticas de direitos humanos.

$\mathrm{O}$ direito à diferença está baseado na idéia de que todos são diferentes entre si; e, propriamente, isto é ser humano, em sua singularidade. Para conceituar a 'natureza humana', deve-se, portanto, respeitar as singularidades. Isso faz com que seja necessário assumir a complexidade da diversidade, ${ }^{7}$ que é a marca mais concreta da 'natureza humana', onde cabe lugar para o reconhecimento do índio, do negro, do branco europeu, do nipo-brasileiro, do sírio-libanês, da mulher, do homem idoso, da mulher homossexual, da criança, do artesão, do intelectual, do bancário, do deficiente, do espírita, do pentecostal, do católico... e isso porque todos temos 'algo em comum' e este 'algo em comum' tem a ver com a igual possibilidade de sermos responsáveis pelo respeito à alteridade e, por isso, considerados pertencentes à comunidade dos que fruem de direitos, na medida concreta de sua condição. Torna-se imperioso, portanto, para as sociedades contemporâneas que sejam capazes de promover e permitir o igual acesso ao reconhecimento, tendo nisto um ponto de encontro de uma comunidade organizada de cidadãos.

\section{A percepção estética da diferença: a justificação antropológica da alteridade}

A melhor forma de respeito à condição humana é a garantia do reconhecimento da reserva de lugar para a diferença do outro. Não existe alteridade sem diversidade (diversidade étnica, cultural, ideológica, estética...), ${ }^{8}$ e esta é uma conclusão que nos convida a praticar uma visão de mundo descentrada, único caminho para o trânsito intersubjetivo. A diluição do olhar auto-centrado é um dos efeitos do processo de aproximação entre as categorias do justo e do belo.

E aqui, particularmente, a teoria estética tem alguma contribuição a trazer. E isto porque as práticas estéticas transbordam de significações. A arte, se bem observada,

\footnotetext{
Não por outro motivo, as mais recentes normas de direitos humanos já registram e consagram esta lógica como forma de efetivação dos direitos humanos, a exemplo do que se pode ler no Preâmbulo da Declaração das Nações Unidas sobre os Direitos dos Povos Indígenas (2007): “Afirmando que os povos indígenas são iguais a todos os demais povos e reconhecendo ao mesmo tempo o direito de todos os povos a serem diferentes, a se considerar a si mesmos diferentes e a serem respeitados como tais", e, "Afirmando também que todos os povos contribuem para a diversidade e a riqueza das civilizações e culturas, que constituem patrimônio comum da humanidade" (grifos nossos).

8 A diversidade aqui não é somente a diversidade dos povos, mas a diversidade que se dá também dentro de um mesmo grupo social, de uma sociedade, ou de uma cultura: "Com efeito, o problema da diversidade não é levantado apenas a propósito de culturas encaradas em suas relações recíprocas; ele existe também no seio de cada sociedade, em todos os grupos que a constituem: castas, classes, meios profissionais ou confessionais etc desenvolvem certas diferenças às quais cada grupo atribui uma importância imensa" (LÉVI-STRAUSS, Claude. Antropologia estrutural dois. 4. ed. Tradução de Maria do Carmo Pandolfo. Rio de Janeiro: Tempo Brasileiro, 1993. p. 332).
} 
acaba sendo um convite a outrar-se, a olhar em volta, e a perceber outros rostos, outras formas, outras interpretações, outras visões, outras lógicas. A arte, portanto, ao dizer muito sobre os humanos, que já passaram e que estão entre nós, diz alguma coisa sobre a dissonância dos gostos, das tendências, das vontades... Há tendências, escolas, movimentos, estilos, culturas, métodos, formas, lógicas [tudo sempre no plural], quando se trata de falar das artes. O samba brasileiro de Adoniran Barbosa é tão arte quanto o fado português, e quanto as sonatas iluministas para cravo e cordas. Por isso, não há uma arte universal, não há uma arte única globalmente, salvo aquela produzida por imposição da indústria cultural como forma anti-democrática de padronização do gosto. ${ }^{9}$ Por isso, a arte nos diz algo; o que ela diz, não quer calar: ela diz que somos profundamente diferentes uns dos outros, e diz, também, em voz tonitruante, que há muita beleza no interior das diferenças. Ler beleza na diferença da arte do outro é abrir-se para a contribuição que cada um é capaz de trazer na projeção de formas para o belo, e, por isso, para a existência.

Certamente, a estética, como forma de expressão, ao dizer de nós, nos permite contemplar a nós mesmos, ou seja, sua função é nos levar a nós mesmos, a nos conhecermos, a conhecermos emoções internas, padrões de comportamento, traços de personalidade, virtudes e vícios, habilidades e competências, gênio e revolta, romantismo ou idealismo. A profusão de tendências, estilos e gostos nos obriga a ter de reconhecer que não existe um padrão estético. Se não existe um padrão de gosto, ou um padrão obrigatório para medir o belo/feio (o feio pode ser belo e o belo pode ser feio), então, a consciência da estética nos traz a consciência da diversidade. Seguindo Pablo Picasso, pode-se dizer que: "A arte é mentira que nos permite conhecer a verdade". Do ponto de vista filosófico, o que ela nos faz conhecer é que não somos iguais. Mais, ainda, deve-se ser enfático neste ponto, não podemos ser igualizados, nem pela planificação social e nem pela padronização capitalista que forja o homem unidimensional, ${ }^{10}$ sob pena de nos perdermos de nós mesmos, de nossa auto-identidade, de nossos sentimentos, vocações e perspectivas absolutamente singulares, aquelas que são próprias da condição, existencial e histórica, individual humana.

Estas significações têm de ser interpretadas e reconstruídas, especialmente quando se pretende, a partir de uma teoria estética crítica, revelar proximidades entre as cinco sílabas que compõem o termo gosto e as cinco sílabas que compõem o termo justo,

\footnotetext{
9 "Como depois explicou Adorno, a expressão indústria da cultura foi escolhida por Horkheimer e por ele, em Dialética do esclarecimento, por suas conotações antipopulistas. A Escola de Frankfurt criticava a cultura de massa não pode ela ser democrática, mas justamente por não sê-lo. A concepção de cultura popular, afirmavam, era ideológica; a indústria da cultura oferecia uma cultura falsa, não espontânea e reificada, em vez da coisa verdadeira" (JAY, Martin. op. cit., p. 277).

10 A respeito, vide MARCUSE, Herbert. A ideologia da sociedade industrial. 4. ed. Rio de Janeiro: Zahar, 1973. p. 10 e ss.
} 
ao menos em língua portuguesa. Uma destas significações das práticas estéticas é a de que o dissenso é um elemento da vida social. O dissenso, que se manifesta também por várias formas, como pela querença de coisas diversas, como pelo gosto de coisas diversas, como por vontades próprias, por juízos de valor diversos, como formas de perceber as tramas sociais e humanas díspares entre si. O dissenso é um elemento ineliminável da vida social e deve ser absorvido pelas práticas políticas sob pena de se menosprezar o conteúdo das valiosas transformações trazidas pelas lutas recentes e históricas de Maio de 68, em Paris, como em Frankfurt. ${ }^{11}$ Este momento histórico, e seus resultados sociais, restauram no ambiente social a possibilidade da releitura de Nietzsche, para quem: "É na posse que a diferença entre os homens se revela com mais vigor. Esta diferença se manifesta na diversidade de seus juízos de valor, no fato de serem diferentes e em que não opinam do mesmo modo sobre certos valores". ${ }^{12}$

Neste sentido, é isto que a estética nos faz perceber: a diferença do outro, ainda que no outro queiramos encontrar apenas a igualdade, a igualdade que nos faz, por exemplo, comuns por sermos humanos. As multicoloridas formas de expressão do que é a diversidade humana são fundamentais à condição humana, e, por isso, compõem o leque das vastas afirmações culturais humanas. ${ }^{13}$ Democrático, livre a aberto é o mundo onde a dança, o culto, a tradição, o êxtase espiritual, o saber comum, a ciência, as formas culturais, e o folclore popular têm seu lugar. Trata-se de um mundo onde também o amor ao dissemelhante é possível, um trânsito que enlaça a alteridade pela pujança da estética e do interlúdio comunicativo proporcionado pela linguagem simbólica da arte. É de Adorno a afirmação segundo a qual: "O amor é a capacidade de perceber o semelhante no dissemelhante" (grifo nosso). ${ }^{14} \mathrm{O}$ amor aos vários estilos como o amor às várias iniciativas culturais, e como amor às várias identidades antropológicas e formas de manifestação da humanidade é um amor à própria condição humana tal qual se mostra aos olhos humanos, nem mais nem menos.

No centro de toda esta preocupação está o problema de como se constitui o olhar para enxergar o outro. Isso significa pensar e agir de forma a considerar o outro não

${ }_{11}$ A respeito, vide BITTAR, Eduardo C. B. O direito na pós-modernidade e reflexões frankfurtianas. 2. ed. Rio de Janeiro: Forense Universitária, 2009. p. 10 e ss.

12 NIETZSCHE, Friedrich. Além do bem e do mal: prelúdio de uma filosofia do futuro. TraduçãoArmando Amado Júnior. São Paulo: WVC, 2001. p. 129.

13 Sobra a imensa variedade de culturas que forma um grande quadro da diversidade humana, se pronuncia Lévi-Strauss: "Impõe-se uma primeira constatação: a diversidade das culturas humanas é, de fato no presente, de fato e também de direito no passado, muito maior e mais rica do que tudo aquilo que delas pudermos chegar a conhecer" (LÉVI-STRAUSS, Claude. Antropologia estrutural dois. 4. ed. Tradução de Maria do Carmo Pandolfo. Rio de Janeiro: Tempo Brasileiro, 1993. p. 331).

14 ADORNO, Theodor W. Minima moralia. Tradução de Arthur Morão. Lisboa: Edições 70, 2001. II, 143, p. 196. 
como estranho ou estrangeiro, como alheio às práticas de mim, mas como ente autônomo, constituído em meio a práticas que são próprias e únicas, e, por isso, tão válidas quanto as minhas. A questão do olhar sobre o outro e a questão da interpretação da cultura do outro se cruzam para desembocar no debate sobre o etnocentrismo e suas formas de expressão. Seguindo Richard Rowland, o etnocentrismo “...a tendência a considerar a cultura de seu próprio povo como a medida de todas as coisas - é uma tentação que deve ser evitada". ${ }^{15}$

Tudo fala a favor do estranhamento; a linguagem, o vestuário, as práticas, os saberes, as crenças, as identidades, os gostos, os hábitos alimentares, os padrões morais. As diferenças assustam, pela incompreensão que produzem, e geram, do ponto de vista de reações psico-sociais, medo e exclusão. Mas, ainda com Rowland, "Não se pode considerar inferior aquilo que é apenas diferente". ${ }^{16}$ A recusa do etnocentrismo é um esforço da civilização, pois também uma pulsão primitiva nos conduz à inaceitação do outro. Daí o clássico estudo de Claude Lévi-Strauss, Race et histoire, guardar sua atualidade, como esforço de condução do olhar antropológico em favor do cultivo da diferença e do respeito à identidade do outro. ${ }^{17} \mathrm{~A}$ recusa ao etnocentrismo faz parte de um esforço em favor da dignidade da pessoa humana e de sua idéia como valor de encontro entre os povos e entre as diferenças existentes entre as pessoas.

Uma sociedade socializada com estas preocupações cultiva o espírito necessário para o exercício de um pluralismo democrático, superador do homogeneísmo moderno, ordenador, e totalitário, para o qual vale a equação mortífera de Auschwitz como lugar de conversão do inconversível - do judeu a não-judeu, ou seja, do judeu a cinzas e pó. O esforço democrático, numa leitura adorniana, é o esforço pelo não-retorno, ou o esforço libidinal pela recusa na recaída produzida por Auschwitz. ${ }^{18} \mathrm{E}$ isto porque a disseminação da semente da unilateralidade e do gosto por uma única doutrina somente pode descambar na afirmação de formas políticas de profundo desrespeito para o diverso.

15 ROWLAND, Robert. Antropologia, história e diferença: alguns aspectos. 3. ed. Porto: Afrontamento, 1997. p. 7.

16 Id. Ibid., p. 08.

17 "O lócus classicus dessa recusa antropológica do etnocentrismo é o conhecido ensaio de Claude Lévi-Strauss, Race et históire" (Id. Ibid.).

18 "Entre as intuições de Freud que realmente também alcançam o domínio da cultura e da sociologia, uma das mais profundas, a meu ver, é a de que a civilização engendra por si mesma o anticivilizatório e o reforça progressivamente. As suas obras O mal-estar na civilização e Psicologia de grupo e a análise do ego mereceriam a maior difusão, precisamente em relação a Auschwitz. Se a barbárie está no próprio princípio da civilização, então a luta contra esta tem algo de desesperador" (ADORNO, Theodor W. Palavras e sinais: modelos críticos 2. Petrópolis: Vozes, 1995. p. 105). 
4. Amor e reconhecimento: a ética do cuidado e a cultura dos direitos humanos

A dignidade da pessoa humana, por sua natural complexidade, demanda uma série de cuidados. Tomando-se na expressão dignidade da pessoa humana o princípio que meta-formata e ajusta o direito a um conjunto de exigências afirmadoras da condição humana, pode-se dizer, com Eric Fromm, que uma cultura centrada nos direitos humanos é uma cultura que acena positivamente em direção à erotização do mundo, ${ }^{19}$ à biofilia e à tolerância, negando os caminhos modernos da biopolítica e do extermínio do outro como forma de realização mesmo dos projetos emancipatórios. ${ }^{20}$

O revisionismo crítico da modernidade implica nisto, na consciência da necessidade de um lugar para o amor no interlúdio das relações sociais, abrindo campo para a reflexão acerca do cuidado de si como ética e do cuidado do outro como expressão da responsabilidade ativa, para pensar com Erich Fromm. ${ }^{21} \mathrm{O}$ amor, de fato, como primeira forma de pertença ao mundo, tem a ver com este contato, a princípio estabelecido no laço maternal e provedor da primeira hora da existência. E é exatamente numa trilha psicanalítica que, baseando-se em estudos de Freud, Mead e Winicott, Axel Honneth percebe a atualidade do jovem Hegel, para afirmar: "Para Hegel, o amor representa a primeira etapa de reconhecimento recíproco, porque em sua efetivação os sujeitos se confirmam mutuamente na natureza concreta de suas carências, reconhecendo-se assim como seres carentes; na experiência recíproca da dedicação amorosa, dois sujeitos se sabem unidos no fato de serem dependentes, em seu estão carencial, do respectivo outro". ${ }^{22}$ A falta, a percepção de total dependência, é o que marca o primeiro lance de contato com o mundo.

Mas, além da carência, o amor pressupõe um segundo movimento, para se realizar como reconhecimento, que é, além da proximidade, a distância. "Uma vez que essa experiência tem de ser mútua na relação do amor, o reconhecimento designa aqui o

19 "O mundo erotizado é um mundo onde eros deixou de ser confundido com o impulso genital específico. É um mundo que se mostra como uma emanação do princípio da vida" (DORIA, Francisco Antonio. Marcuse. 3. ed. Rio de Janeiro: Paz e Terra, 1983. p. 202).

20 A advertência de Eric Fromm é de notória importância para inspirar o pensamento da tolerância: “... Do ponto de vista da lógica paradoxal, a ênfase não é posta no pensamento, mas no ato. Essa atitude tem várias outras conseqüências. Em primeiro lugar, ela leva à tolerância que encontramos no desenvolvimento religioso indiano e chinês. Se o pensamento correto não é a verdade suprema, nem o caminho para a salvação, não há motivos para combater outros, cujo pensamento chegou a formulações diferentes. Essa tolerância é lindamente expressa na história de vários homens a quem foi pedido que descrevessem um elefante no escuto. Um deles, tocando seu tronco, disse: "esse animal é como um cano d'água"; o outro, tocando a orelha, disse: "esse animal parece um leque"; um terceiro, tocando as pernas, descreveu o animal como um pilar..." (FROMM, Eric. A arte de amar. Tradução de Eduardo Brandão. São Paulo: Martins Fontes, 2006. p. 98).

21 “... Ela se sente responsável por seus semelhantes, tanto quanto se sente responsável por si...” (Id. Ibid., p. $35)$.

22 HONNETH, Axel. Luta por reconhecimento: a gramática moral dos conflitos sociais. Tradução de Luis Repa. São Paulo: Editora 34, 2003. p. 160. 
duplo processo de uma liberação e ligação emotiva simultâneas da outra pessoa; não um respeito cognitivo, mas sim uma afirmação da autonomia, acompanhada ou mesmo apoiada pela dedicação, é ao que se visa quando se fala do reconhecimento como um elemento constitutivo do amor". ${ }^{23} \mathrm{O}$ cuidado de quem ama é o cuidado de quem está perto, quando é necessário estar perto, e de quem não interfere, quando é necessário não interferir.

A ética do cuidado se funda na estratégia do amor, e, por isso, ela deve ser tomada como base para o desenvolvimento de uma cultura dos direitos humanos. Isso não significa, e a advertência segue a linha de raciocínio de Honneth, que seja possível estender o amor para todos, pois o amor se desenvolve num pequeno grupo de laços humanos. Isso também não significa que a cultura do direito deva orientar-se e fundamentar-se pela difícil lógica do amor, de quando ele ocorre e de quando ele não ocorre. Em verdade, respaldar a justificação do desenvolvimento de uma cultura dos direitos humanos na base de uma ética do cuidado significa estender as táticas e estratégias de atuação do amor para o campo das políticas públicas e formas de distribuição do direito. $\mathrm{O}$ amor promove a vida, e este caráter é próprio da lógica biofílica, pois “... além do elemento dação, o caráter ativo do amor se torna evidente no fato de que sempre implica certos elementos básicos, comuns a todas as formas de amor. São elas cuidado, responsabilidade, respeito e conhecimento...". ${ }^{24}$ Assim, também, amor e direito ganham uma irmandade inseparável.

Nesta perspectiva, o cultivo desses valores é de fundamental importância para o desenvolvimento de uma genuína forma de interação social, na qual, de fato, se possa falar de democracia e de direitos humanos, exatamente porque ego e alter se colocam no centro das preocupações da técnica, do progresso, da economia e da política. Inclusive, se trata de pensar o próprio aprimoramento da democracia e da cultura dos direitos humanos na base de uma ampla conexão das práticas sociais a práticas ligadas a uma ética do cuidado, onde o feminino joga um papel determinante. ${ }^{25}$ Se não há direitos humanos sem respeito, o respeito significa aqui a capacidade de amar e deixar se desenvolver integralmente, e não o dominar, o castrar, o manipular; uma ética do cuidado exala respeito, porque cultiva o poder do afeto como forma de "olhar com atenção" (respiecere). ${ }^{26}$ Por isso, a educação

23 HONNETH, Axel. Luta por reconhecimento: a gramática moral dos conflitos sociais. Tradução de Luis Repa. São Paulo: Editora 34, 2003. p. 178.

24 FROMM, Eric. op. cit., p. 33.

25 “... Assim, a anima, arquétipo da democracia, através de seus atributos, em especial da inventividade e do sentimento, pode surgir como agente catalisador da transformação do magistrado para atender a esse anseio coletivo. Em toda sua obra, Byington tem ressaltado a importância, na psique coletiva, da democracia, entendida como um processo de livre interação das polaridades em função do todo (por exemplo, povogoverno) sem que ocorra uma identificação com um dos lados de qualquer polaridade. Para o autor, os valores da democracia apenas serão atingidos no dinamismo da alteridade (ou seja, sob a regência do arquétipo do animus/anima)...” (PRADO, Lidia Reis de Almeida. O juiz e a emoção: aspecto da lógica da decisão judicial. 2. ed. Campinas: Millenium, 2003.p. 93).

26 “... A responsabilidade poderia deteriorar-se facilmente em denominação e possessividade, não fosse um 
e a metodologia em (e para) os direitos humanos deve preparar para o convívio com a diversidade, na base do diálogo e do respeito, voltado para a alteridade, como forma de prática de solidariedade social, na base da tolerância.

Inclusive, neste sentido, a biofilia como norte da educação em direitos humanos incentiva a acumulação e a produção de esforços sociais e reflexivos, ativos e teóricos, no sentido da proliferação de condições de cultivo e desenvolvimento pró-ativos das dimensões realizadoras da dignidade humana. $\mathrm{O}$ caráter ativo da política do amor envolve necessariamente uma atitude pró-ativa perante o mundo que, entre outras coisas, se pronuncia sobre a barbárie, repele a injustiça, se enoja com a desigualdade, promove a cultura da não-violência e se indigna com o sofrimento humano. Uma cultura dos direitos humanos deve envolver, por isso, táticas de recolhimento das energias eróticas que pulsam a favor da biofilia e da política do amor, esta que é conjuntiva e não disruptiva. ${ }^{27}$

O cuidado com a condição humana expressa a necessidade de cultivarmos um espírito aberto e incentivador do princípio da vida (éros), cuidando para que haja respeito para com a multiplicidade de rostos e gostos, vocações e corações, formas corpóreas e estilos, pensamentos e competências, habilidades e limitações, olhares e perspectivas, vícios e virtudes, atrações e visões, empatias e antipatias, tendências, leituras e vontades. Neste sentido, afirma Nietzsche, em Além do bem e do mal: "Viver é querer ser diferente da Natureza, formar juízos de valor, preferir, ser injusto, limitado, querer ser diferente!". ${ }^{28}$

Onde não há espírito tolerante, compreensão e diálogo, há imposição, castração, limitação, restrição, determinação. Os resultados deste processo somente podem ser o ódio, a competição, a rebelião, a eliminação, a opressão, e o totalitarismo. O amor e o afeto se distinguem destas formas de expressão do convívio opressor, exatamente porque possibilitam a existência do outro enquanto outro. E isso porque o amor pelo mesmo é simplesmente amor narcísico, ou seja, não se trata de amor, mas de auto-contemplação de si mesmo. A aceitação da diversidade caminha para a construção do roteiro do amor, como prática de entrega e aconchego no outro enquanto diferente, pois o amor ao outro enquanto o mesmo é simplesmente egoísmo disfarçado de amor.

terceiro componente do amor, o respeito. Respeito não é medo e temor reverente; ele denota, conforme a própria raiz da palavra (respiecere = olhar com atenção), a capacidade de ver uma pessoa como ela é, ter consciência da sua individualidade. Respeito significa a preocupação com que o outro cresça e se desenvolva tal como é..." (FROMM, Eric. op. cit., p. 35).

27 “... O amor é uma atividade, não um afeto passivo; ele é um "manter-se ligado", não é uma simples "queda". De um modo geral, o caráter ativo do amor pode ser descrito afirmando-se que amar é principalmente dar, e não receber..." (Id. Ibid., p. 28).

28 NIETZSCHE, Friedrich. Além do bem e do mal: prelúdio de uma filosofia do futuro. TraduçãoArmando Amado Júnior. São Paulo: WVC, 2001. p. 27. 
O amor verdadeiro, portanto, não pratica nem o julgamento mordaz, nem a crítica severa, nem a manutenção da tradição pela tradição, nem exercita o olhar ácido e excludente da alteridade, que são os grandes responsáveis germinais por provocar o sofrimento. ${ }^{29} \mathrm{O}$ amor é a única linguagem capaz de fazer com que os pais heterossexuais consigam lidar com filhos homossexuais, com que a mãe continue amando o filho preso como réu confesso. Não por outro motivo, o pensamento filosófico de Axel Honneth se detém em considerar que as categorias do amor, do direito e da solidariedade são as três fundamentais bases de construção do reconhecimento do outro, e, por isso, três pilares para a constituição da intersubjetividade necessária para a construção dos laços sociais. Sem estas, o sofrimento aparece como matriz das lutas sociais e das injustiças. ${ }^{30}$

\section{Conclusão}

Esta investigação empreende um movimento em direção à afirmação e fundamentação filosófica da diversidade humana. Dialogando com fontes da antropologia, também reitera o compromisso de construção política de uma forma não-autoritária do olhar, valor fundamental para a construção do espírito democrático. Trabalha a noção de dignidade como capaz de abrigar em seu bojo as idéias de igualdade e diferença. Identifica a idéia de que uma cultura dos direitos humanos centrada numa ética do pluralismo e da diversidade deve cultivar: abertura democrática, aceitação da alteridade, múltiplas formas de expressão, inclusão de minorias, proteção da diversidade dos jogos de linguagem social, porosidade ético-antropológica, sensibilidade social e cultural. A partir desta linha de análise, se torna possível afirmar na cultura dos direitos humanos fundada na diversidade, uma forma de garantir que o olhar sobre o humano se desprenda da categoria do universal, e busque o reconhecimento da humanidade tal como se apresenta materialmente e historicamente, como individualidade. Neste sentido, reforça-se o impacto do pensamento pós-moderno, com a cultura da diversidade e do pluralismo, para falar a respeito da idéia da dignidade da pessoa humana como um fator nuclear de fundamentação e legitimação de uma cultura dos direitos humanos, onde as diversas formas de convergências humanas podem se estruturar em práticas fundantes do convívio democrático, pluralista, dialógico, aberto e tolerante.

São Paulo, fevereiro de 2009.

\footnotetext{
29 A respeito, vide HONNETH, Axel. Sofrimento de indeterminação: uma reatualização da filosofia do direito de Hegel. São Paulo: Editora Singular, 2007.

30 Id. Luta por reconhecimento: a gramática moral dos conflitos sociais. Tradução de Luis Repa. São Paulo: Editora 34, 2003. p. 155-212.
} 


\section{Referências}

ADORNO, Theodor W. Indústria cultural. Tradução de Julia Elisabeth Levy (et al). São paulo: Paz e Terra, 2002.

. Minima moralia. Tradução de Artur Morão. Lisboa: Edições 70, 2001.

. Teoria estética. Tradução de Artur Morão. Lisboa: Edições 70, 2006.

; HORKHEIMER, Max. Dialética do esclarecimento. Tradução de Guido Antonio de Almeida. Rio de Janeiro: Jorge Zahar, 1985.

BARZOTTO, Luiz Fernando. Pessoa e reconhecimento: uma análise estrutural da dignidade da pessoa humana. Revista Brasileira de Filosofia, São Paulo, v. 232, p. 78-106, 2009.

BITTAR, Eduardo C. B. O direito na pós-modernidade e reflexões frankfurtianas. 2. ed. Rio de Janeiro: Forense Universitária, 2009.

. Filosofia crítica e filosofia do direito: por uma filosofia social do direito. Revista Cult, São Paulo, Dossiê Filosofia do Direito: o que foi, e o que é que será?”, a. 10, n. 112, p. 53-55, abr. 2007.

CANDÉ, Roland de. História universal da música. Tradução de Eduardo Brandão. São Paulo: Martins Fontes, 1994. v. 1.

. História universal da música. Tradução de Eduardo Brandão. São Paulo: Martins Fontes, 1994. v. 2.

CARVALHO, José Jorge de. O olhar etnográfico e a voz subalterna. Brasília: Departamento de Antropologia da Unb, 261, Série Antropologia, 1999.

DORIA, Francisco Antonio. Marcuse. 3. ed. Rio de Janeiro: Paz e Terra, 1983.

ECO, Umberto. História da beleza. Tradução de Eliana Aguiar. Rio de Janeiro: Record, 2007.

. História da feiúra. Tradução de Eliana Aguiar. Rio de Janeiro: Record, 2007.

FOUCAULT, Michel. A ética do cuidado de si como prática da liberdade. In: ÉTICA, sexualidade, política, Ditos e escritos (V). Tradução de Elisa Monteira; Inês Autran Dourado Barbosa. Rio de Janeiro: Forense Universitária, 2004.

FREUD, Sigmund. Além do princípio de prazer. In: OBRAS completas. Rio de Janeiro: Imago, 1999. v.18, p. 17-75.

Imago, 1997.

. O mal-estar na civilização. Tradução de José Octávio de Aguiar Abreu. Rio de janeiro:

FROMM, Eric. Anatomia da destrutividade humana. 2. ed. Tradução de Maço Aurélio de Moura Matos. Rio de Janeiro: Guanabara, 1987. 
. A arte de amar. Tradução de Eduardo Brandão. São Paulo: Martins Fontes, 2006.

. La revolución de la esperanza. Daniel Jiménez Catillejo. México: Fondo de Cultura Económica, 2003.

GIANOTTI, José Arthur. Moralidade pública e moralidade privada. In: NOVAES, Adauto (Org.) Ética. São Paulo: Companhia das Letras; Secretaria Municipal de Cultura, 1992. p. 239-245.

GIOVANNETTI, Marcio de Freitas. O sujeito e a lei. In: GROENINGA, Giselle; PEREIRA, Rodrigo da Cunha (Coords.). Direito de família e psicanálise: rumo a uma nova epistemologia. Rio de Janeiro: Imago, 2003. p. 43-53.

HÄBERLE, Peter. A dignidade humana e a democracia pluralista - seu nexo interno. In: SARLET, Ingo Wolfgang. Direitos fundamentais, informática e comunicação. Porto Alegre: Livraria do Advogado, 2007. p. 11-28.

HABERMAS, Jürgen. Consciência moral e agir comunicativo. Tradução de Guido A. de Almeida. Rio de Janeiro: tempo Brasileiro, 1989.

. Direito e democracia: entre facticidade e validade. v. I. 2. ed. Tradução de Flávio Beno Siebeneichler. Rio de Janeiro: Tempo Brasileiro, 2003.

. Direito e democracia: entre facticidade e validade. v. II. 2. ed. Tradução de Flávio Beno Siebeneichler. Rio de Janeiro: Tempo Brasileiro, 2003.

. A inclusão do outro: estudos de teoria política. Tradução de George Spencer; Paulo Astor Soethe. São Paulo: Loyola, 2002.

HELLER, Agnes; FÉHER, Ferenc. A condição politica pós-moderna. Tradução Marcos Santarrita. Rio de Janeiro: Civilização Brasileira, 1998.

HONNETH, Axel. Disrespect: the normative foundations of Critical Theory. Cambridge: Polity, 2008 .

. Justiça e liberdade comunicativa: reflexões em conexão com Hegel, in Revista Brasileira de Estudos Políticos, Belo Horizonte, Universidade Federal de Minas Gerais, n. 89, ps. 101-120, jan./ jun. 2004.

. Luta por reconhecimento: a gramática moral dos conflitos sociais. Tradução de Luiz Repa. São Paulo: Editora 34, 2003.

. Sofrimento de indeterminação: uma reatualização da filosofia do direito de Hegel. Tradução de Rúrion Soares Melo. São Paulo: Editora Singular, Esfera Pública, 2007.

HORKHEIMER, Max. Eclipse da razão. Tradução Sebastião Uchoa Leite. São Paulo: Centauro, 2002.

JAY, Martin. A imaginação dialética: história da Escola de Frankfurt e do Instituto de Pesquisas Sociais. Tradução de Vera Ribeiro. Rio de Janeiro: Contraponto, 2008. 
LÉVI-STRAUSS, Claude. Antropologia estrutural dois. 4. ed. Tradução de Maria do Carmo Pandolfo. Rio de Janeiro: Tempo Brasileiro, 1993.

. Tristes trópicos. Tradução de Rosa Freire D’Aguiar. São Paulo: Companhia das Letras, 1996.

LYOTARD, Jean-François. A condição pós-moderna. 2. ed. Tradução de José Bragança de Miranda. Lisboa: Gradiva, 1989.

MARCUSE, Herbert. A dimensão estética. Tradução de Maria Elisabete Costa. Lisboa: Edições 70, 2007.

- Eros e civilização: uma interpretação filosófica do pensamento de Freud. Tradução de Álvaro Cabral. 8. ed. Rio de Janeiro: LTC, 1999.

. A grande recusa hoje. Tradução de Isabel Loureiro e Robespierre de Oliveira. Rio de Janeiro: Vozes, 1999.

. A ideologia da sociedade industrial. 4. ed. Rio de Janeiro: Zahar, 1973.

MATOS, Olgária C. F. A Escola de Frankfurt: luzes e sombras do iluminismo. 2. ed. São Paulo: Moderna, 2005.

MELO, Eduardo Rezende. Nietzsche e a justiça: crítica e transvaloração. São Paulo: Perspectiva; FAPESP, 2004.

NIETZSCHE, Friedrich W. Além do bem e do mal: prelúdio de uma filosofia do futuro. Tradução Armando Amado Júnior. São Paulo; WVC, 2001.

PRADO, Lídia Reis de Almeida. O juiz e a emoção: aspecto da lógica da decisão judicial. 2. ed. Campinas: Millenium, 2003.

ROWLAND, Robert. Antropologia, história e diferença: alguns aspectos. 3. ed. Porto: Afrontamento, 1997.

SAAVEDRA, Giovanni A. Hermenêutica constitucional, democracia e reconhecimento. Revista Brasileira de Direito Constitucional, São Paulo, v. 7, p. 265-291, 2006. 